Jurnal Ilmiah Ibnu Sina, 6(2), Oktober 2021, 312-321

p-ISSN: 2502-647X; e-ISSN: 2503-1902

\title{
PENGARUH EDUKASI BOOKLET IMUNISASI DASAR TERHADAP PENGETAHUAN DAN SIKAP ORANG TUA MASA PANDEMI COVID-19
}

\author{
Eny Hastuti ${ }^{1 *}$, Sari Wahyunita ${ }^{2}$, Aesty Rahayu ${ }^{2}$, Wahyudi ${ }^{2}$ \\ ${ }^{1}$ Program Studi S1 ARS, STIKES Borneo Lestari \\ ${ }^{2}$ Program Studi S1 Farmasi, STIKES Borneo Lestari \\ *Email: enyhastuti245@gmail.com
}

Artikel diterima: 21 Agustus 2021; Disetujui: 27 September 2021

DOI: https://doi.org/10.36387/jiis.v6i2.736

\begin{abstract}
ABSTRAK
Pemerintah Indonesia mengambil beberapa langkah untuk memastikan pengendalian COVID-19 dan memperkuat kapasitas sistem pelayanan kesehatan untuk menangani masa pandemi. Salah satunya adalah cakupan imunisasi dasar untuk mencegah penyakit pada anak-anak seperti campak, rubella, dan difteri yang semakin menurun diantaranya angka cakupan imunisasi difteri, pertusis, tetanus (DPT3) dan campak serta rubella (MR1) berkurang lebih dari 35\%. Layanan imunisasi dibuka kembali untuk mecegah Kejadian Luar Biasa (KLB) penyakit pada anak yang dapat dicegah dengan imunisasi (PD3I), mensosialisasikan serangkaian pedoman, standar operasi prosedur (SOP), serta komunikasi, informasi, dan edukasi (KIE). Penelitian ini bertujuan untuk mengetahui pengaruh edukasi media booklet imunisasi dasar terhadap pengetahuan dan sikap orang tua masa pandemi COVID-19. Rancangan Penelitian Nonrandomized pre-test post-test with control group design. Jumlah sampel 158 responden dibagi 2 kelompok, kelompok intervensi yang diedukasi dengan media booklet dan kelompok kontrol tanpa edukasi booklet. Hasil penelitian didapatkan edukasi media booklet sangat berpengaruh $(p=0,001)$ terhadap pengetahuan dan sikap orang tua tentang imunisasi dasar pada masa pandemic COVID-19, hal ini membuktikan bahwa media booklet merupakan alat komunikasi yang dapat digunakan oleh tenaga kesehatan untuk membantu meningkatkan pengetahuan orang tua agar tidak khawatir membawa anak ke pelayanan kesehatan untuk tetap melakukan imunisasi pada masa pandemi COVID-19.
\end{abstract}

Kata Kunci : Booklet, pengetahuan, sikap, COVID-19

\section{ABSTARCT}

The Indonesian government is taking several steps to ensure the control of COVID-19 and strengthen the capacity of the health care system to handle the pandemic period. One of them is the coverage of basic immunization to prevent diseases in children such as measles, rubella, and diphtheria which is decreasing, including the number of immunization coverage for diphtheria, pertussis, tetanus (DPT3) and measles and rubella (MR1) has decreased by more than 35\%. Immunization services are reopened to prevent Extraordinary Events (KLB) of diseases in children that can be prevented by immunization (PD3I), to socialize a 
Jurnal Ilmiah Ibnu Sina, 6(2), Oktober 2021, 312-321

p-ISSN: 2502-647X; e-ISSN: 2503-1902

series of guidelines, standard operating procedures (SOP), as well as communication, information, and education (KIE). This study aims to determine the effect of booklet media education on parents' knowledge and attitudes towards basic immunization during the COVID-19 pandemic. Research Design Nonrandomized pre-test post-test with control group design. The total sample of 158 respondents was divided into 2 groups, the intervention group which was educated with booklet media and the control group without booklet education. The results showed that booklet media education was very influential $(p=0.001)$ on parents' knowledge and attitudes about basic immunization during the COVID19 pandemic, this proves that booklet media is a communication tool that can be used by health workers to help increase parents' knowledge so as not to worry about bringing children to health services to keep immunizing during this COVID-19 pandemic.

Keywords: Booklet, knowledge, attitudes, the COVID-19

\section{PENDAHULUAN}

Imunisasi merupakan upaya

kesehatan masyarakat paling efektif dan efisien dalam mencegah beberapa penyakit berbahaya. Peran imunisasi dapat menyelamatkan masyarakat dunia dari kesakitan, kecacatan bahkan kematian akibat penyakit-penyakit seperti Cacar, Polio, Tuberkulosis, Hepatitis B yang dapat berakibat pada Kanker Hati, Difteri, Campak, Rubela dan Sindrom Kecacatan Bawaan Akibat Rubela, Tetanus pada ibu hamil dan bayi baru lahir, Pneumonia (radang paru), Meningitis (radang selaput otak), hingga kanker Serviks yang disebabkan oleh infeksi Human Papilloma Virus (Kemenkes, 2020).

Sejak Indonesia melaporkan kasus COVID-19 pertama pada bulan
Maret 2020, layanan imunisasi rutin untuk mencegah penyakit-penyakit pada anak - anak seperti Campak, Rubela, dan Difteri semakin menurun. Berdasarkan data yang didapatkan bahwa imunisasi dasar seperti Difteri, Pertusis, Tetanus (DPT3), Campak, dan Rubela (MR1) pada bulan Mei 2020 berkurang lebih dari $35 \%$ dibandingkan periode waktu yang sama pada tahun sebelumnya. Data dari Kementerian Kesehatan dan UNICEF di bulan April 2020 menunjukkan bahwa layanan imunisasi dari fasilitas kesehatan (Puskesmas dan Posyandu) mengalami penurunan $84 \%$. Beberapa hambatan layanan imunisasi tidak dilaksanakan oleh fasilitas kesehatan adalah 
Jurnal Ilmiah Ibnu Sina, 6(2), Oktober 2021, 312-321

p-ISSN: 2502-647X; e-ISSN: 2503-1902

menurunnya kunjungan imunisasi, petugas pengelola program imunisasi dialihkan ke penanganan COVID, kurangnya komoditas, terbatasnya alat pelindung diri untuk imunisasi yang aman (Kemenkes, 2020; Kemenkes dan UNICEF, 2020).

Pemerintah

Indonesia

melakukan beberapa langkah untuk memastikan pengendalian virus dan memperkuat kapasitas sistem pelayanan kesehatan untuk menangani masa pandemi COVID 19 ini, dengan cara membuka kembali layanan, untuk mencegah kejadian luar biasa. Mensosialisasikan dan mengembangkan serangkaian pedoman, standar operasi prosedur (SOP), dan materi komunikasi, informasi dan edukasi mulai dilakukan ke masyarakat (Kemenkes,2020; Tyas, 2017).

$$
\text { Berdasarkan penelitian }
$$

sebelumnya upaya pemerintah dalam edukasi imunisasi dilakukan penyuluhan dan pemberian booklet pada ibu balita masa pandemi didapatkan hasil bahwa pengetahuan ibu balita sebelum diberikan edukasi sebesar 58,96\%, sesudah diberikan edukasi pengetahuan meningkat 80,68\% (Usman, 2021; Yeni, 2020). Beberapa penelitian selanjutnya tentang edukasi imunisasi masa pandemi juga dilakukan di masyarakat terutama yang mempunyai balita didapatkan bahwa adanya pengaruh penyuluhan dengan media booklet terhadap sikap orang tua menjadi lebih baik tentag imunisasi dasar (Virginia dkk., 2020).

Upaya untuk memberikan edukasi atau pendidikan kesehatan kepada orang tua balita tentang layanan imunisasi dasar sangat penting selama pandemi COVID 19 sesuai prinsip Pencegahan dan Pengendalian Infeksi (PPI), dengan menjaga jarak aman $1-2$ meter sesuai protokol kesehatan dalam pelaksanaan imunisasi yang aman tetap dilaksanakan di pelayanan kesehatan, hal ini merupakan upaya salah satu pendekatan komunikasi dan pendidikan kesehatan melalui media booklet yang tepat untuk mengatasi masalah-masalah yang menjadi perhatian utama (Kemenkes, 2020). 
Jurnal Ilmiah Ibnu Sina, 6(2), Oktober 2021, 312-321

p-ISSN: 2502-647X; e-ISSN: 2503-1902

\section{METODE PENELITIAN}

Penelitian dilakukan pada bulan Maret 2021 - Juli 2021 di Puskesmas Sungai Besar Kota Banjarbaru. Pengambilan data secara Prospektif pada bulan Mei 2021- Juli 2021 di Unit KIA Puskesmas Sungai Besar yang memiliki fasilitas khusus untuk pelayanan imunisasi dan ruang tunggu dan menerapkan protokol 5M. Teknik penelitian adalah survey analitik dengan desain quasy experimental. Populasi penelitian ini adalah orangtua yang memiliki anak < 1 tahun sedangkan sampel 158 orang responden menggunakan kriteria inklusi dan kriteria eklusi pengambilan sampel purposive sampling. Data karakteristik responden digambarkan secara deskriptif, instrumen penelitian berupa kuesioner diberikan melalui google form. Kuesioner berisi pertanyaan tentang pengetahuan dan sikap, sudah teruji validitas dan reabilitas dengan nilai $\mathrm{r}$ hitung $\geq \mathrm{r}$ tabel. Kriteria nilai pengetahuan terbagi menjadi baik (nilai $\mathrm{x} \geq 75 \%$ ), cukup (nilai x 56-74\%), kurang (nilai $\mathrm{x}<55 \%$ ), untuk nilai sikap terbagi menjadi positif ( nilai $\mathrm{x} \geq$ Mean), dan negative (nilai $\mathrm{x}<$ Mean) (Sugiono, 2012).

imunisasi anak lengkap. Metode

\section{HASIL PENELITIAN DAN}

\section{PEMBAHASAN}

Tabel 1. Karakteristik Responden

\begin{tabular}{|c|c|c|}
\hline Karakteristik & $\mathbf{n}$ & $(\%)$ \\
\hline \multicolumn{3}{|l|}{ Umur (Tahun) } \\
\hline Masa Remaja Akhir (17-25 Tahun) & 20 & 12,7 \\
\hline Masa Dewasa Awal ( 26-35 Tahun) & 115 & 72,8 \\
\hline Masa Dewasa Akhir (36-45 Tahun) & 23 & 14,6 \\
\hline \multicolumn{3}{|l|}{ Pekerjaan } \\
\hline Bekerja & 37 & 23,4 \\
\hline Tidak Bekerja & 121 & 76,6 \\
\hline \multicolumn{3}{|l|}{ Pendidikan } \\
\hline Tinggi & 99 & 62,7 \\
\hline Menengah & 35 & 22,2 \\
\hline Dasar & 24 & 15,2 \\
\hline
\end{tabular}

Sumber : Data Primer, 2021

Berdasarkan tabel 1 umur ibu yang paling banyak adalah menunjukkan dari 158 responden, 26-35 thn (masa dewasa awal) 115 
Jurnal Ilmiah Ibnu Sina, 6(2), Oktober 2021, 312-321

p-ISSN: 2502-647X; e-ISSN: 2503-1902

orang $(72,8 \%)$, yang tidak bekerja 121 orang $(76,6 \%)$ dan yang berpendidikan tinggi 99 orang $(62,7 \%)$.

Jumlah sampel 158 responden dibagi menjadi 2 kelompok, kelompok intervensi yang di edukasi dengan media booklet tentang imunisasi dasar pada masa pandemi Covid-19 dan kelompok kontrol tanpa edukasi. Semua responden dilakukan uji pretest dan post test untuk mengetahui pengetahuan dan sikap terhadap imunisasi dasar pada masa pandemi Covid-19.

Tabel 2. Distribusi Frekuensi Pretest dan Postest Pengetahuan Kelompok Intervensi

\begin{tabular}{ccccc}
\hline \multirow{2}{*}{ Pengetahuan } & \multicolumn{3}{c}{ Pretest } & \multicolumn{2}{c}{ Post test } \\
& $\mathrm{n}$ & $\%$ & $\mathrm{n}$ & $\%$ \\
\hline Baik & 0 & 0 & 72 & 91,1 \\
Cukup & 72 & 91,1 & 5 & 6,3 \\
Kurang & 7 & 8,9 & 2 & 2,5 \\
\hline Total & $\mathbf{7 9}$ & & $\mathbf{7 9}$ & $\mathbf{1 5 8}$ \\
\hline
\end{tabular}

Sumber : Data Primer, 2021

Berdasarkan tabel 2. cukup dan 7 orang $(8,9 \%)$ memiliki menunjukkan bahawa pengetahuan responden kelompok intervensi pengetahuan kurang, sedangkan sebelum diberikan edukasi dengan kelompok intervensi yang sudah edukasi media booklet (post test) media booklet (pretest) didapatkan hasil yang paling banyak adalah 72 mengalami peningkatan 72 orang $(91,1 \%)$ yang memiliki pengetahuan orang $(91,1 \%)$ memiliki pengetahuan baik.

Tabel 3. Distribusi Frekuensi Pretest dan Posttest Sikap Kelompok Intervensi

\begin{tabular}{cccccc}
\hline \multirow{2}{*}{ Sikap } & \multicolumn{2}{c}{ Pretest } & \multicolumn{3}{c}{ Posttest } \\
\cline { 2 - 6 } & $\mathrm{N}$ & $\%$ & $\mathrm{n}$ & $\%$ & \\
\hline Positif & 20 & 25,3 & 71 & 89,9 & \\
Negatif & 59 & 74,7 & 8 & 10,1 & \\
\hline Total & $\mathbf{7 9}$ & & $\mathbf{7 9}$ & & $\mathbf{1 5 8}$ \\
\hline
\end{tabular}

Sumber : Data Primer, 2021

Berdasarkan tabel 3. dapat dilihat sikap responden kelompok intervensi sebelum diberikan edukasi media booklet (pretest) terdapat 20 orang $(25,3 \%)$ memiliki sikap positif dan 59 orang $(74,7 \%)$ memiliki sikap negatif, sedangkan kelompok intervensi yang sudah diedukasi media booklet (post test) mengalami peningkatan yaitu 71 orang $(89,9 \%)$ 
Jurnal Ilmiah Ibnu Sina, 6(2), Oktober 2021, 312-321

p-ISSN: 2502-647X; e-ISSN: 2503-1902

yang memiliki sikap positif, dan $(10,1 \%)$ memiliki sikap negatif. mengalami penurunan 8 orang

Tabel 4. Distribusi Frekuensi Pretest dan Posttest Pengetahuan Kelompok Kontrol

\begin{tabular}{crrlll}
\hline \multirow{2}{*}{ Pengetahuan } & \multicolumn{1}{c}{ Pretest } & \multicolumn{2}{c}{ Posttest } \\
& $\mathrm{N}$ & $\%$ & $\mathrm{n}$ & $\%$ & \\
\hline Baik & 2 & 2,5 & 19 & 24,1 & \\
Cukup & 70 & 88,6 & 35 & 44,3 & \\
Kurang & 7 & 8,9 & 25 & 31,6 & \\
\hline Total & $\mathbf{7 9}$ & & $\mathbf{7 9}$ & & $\mathbf{1 5 8}$ \\
\hline
\end{tabular}

Sumber : Data Primer, 2021

Berdasarkan tabel 4. dapat

dilihat pengetahuan responden

kelompok kontrol tanpa diberikan

edukasi media booklet (pretest)

terdapat 2 orang $(2,5 \%)$ memiliki

pengetahuan baik, 70 orang $(88,6 \%)$

memiliki pengetahuan cukup dan 7

orang $(8,9 \%)$ memilki pengetahuan kurang, kemudian dilakukan (post test) tanpa intervensi dengan hasil 19 orang $(24,1 \%)$ yang memiliki pengetahuan baik, 35 orang $(44,3 \%)$ memiliki pengetahuan cukup dan 25 orang $(31,6 \%)$ memiliki pengetahuan kurang.

Tabel 5. Distribusi Frekuensi Pretest dan Posttest Sikap Kelompok Kontrol

\begin{tabular}{cccccc}
\hline \multirow{2}{*}{ Sikap } & \multicolumn{2}{c}{ Pretest } & \multicolumn{3}{c}{ Posttest } \\
\cline { 2 - 6 } & $\mathrm{n}$ & $\%$ & $\mathrm{n}$ & $\%$ & \\
\hline Positif & 21 & 26,6 & 18 & 22,8 & \\
Negatif & 58 & 73,4 & 61 & 77,2 & \\
\hline Total & $\mathbf{7 9}$ & & $\mathbf{7 9}$ & & $\mathbf{1 5 8}$ \\
\hline
\end{tabular}

Sumber : Data Primer, 2021

Berdasarkan tabel 5 dapat dilihat sikap responden kelompok kontrol tanpa edukasi media booklet (pretest) terdapat 21 orang $(26,6 \%)$ memiliki sikap positif, dan 58 orang $(73,4 \%)$ memiliki sikap negatif, kemudian dilakukan (post test) tanpa intervensi dengan hasil 18 orang $(22,8 \%)$ yang memiliki sikap positif, dan 61 orang $(77,2 \%)$ memiliki sikap negatif.
Berdasarkan analisis data dengan uji wilcoxon signed ranks didapatkan nilai $\rho=0,001$, bahwa adanya perbedaan sebelum dan sesudah diberikan edukasi booklet imunisasi dasar terhadap pengetahuan orang tua masa pandemi di wilayah kerja Puskesmas Sungai Besar Kota Banjarbaru tahun 2021.

Kekuatan pengaruh diperoleh dari uji regresi dengan hasil $\rho=$ 
Jurnal Ilmiah Ibnu Sina, 6(2), Oktober 2021, 312-321

p-ISSN: 2502-647X; e-ISSN: 2503-1902

0,69, bahwa ada pengaruh terhadap edukasi media booklet terhadap pengetahuan orang tua tentang imunisasi dasar pada masa pandemic COVID-19.

Hal sama dengan penelitian sebelumnya didapatkan bahwa ada pengaruh antara penyuluhan dengan media booklet terhadap pengetahuan orang tua balita (Yeni dan Kurnia 2020). Pada beberapa penelitian lain juga ditemukan hasil $\alpha \leq 0.05$ artinya adanya hubungan pengetahuan orang tua terhadap imunisasi (Ninik dkk., 2011). Akibat dari pandemi, pemerintah tetapa mengimbau dengan adanya penyuluhan maupun edukasi lainnya dapat meningkatkan kelengkapan imunisasi dasar khususnya orang tua yang mempunyai balita tetap rutin dilaksanakan. Beberapa penelitian lain juga menyatakan bahwa dengan adanya media edukasi seperti booklet dapat meningkatkan pengetahuan sehingga menimbulkan kesadaran untuk melakukan imunisasi lengkap pada balita (Safitri, 2019 dan Usman, 2021).

Berdasarkan analisis uji Wilcoxon signed ranks didapat nilai $\rho=0,002$ artinya adanya perbedaan antara sebelum dan sesudah edukasi booklet tentang imunisasi dasar terhadap sikap orang tua masa pandemi COVID-19 di wilayah kerja Puskesmas Sungai Sungai Besar Kota Banjarbaru tahun 2021.

Kekuatan pengaruh diperoleh dari uji regresi dengan hasil $\rho=$ 0,95 , bahwa ada pengaruh terhadap edukasi media booklet tentang imunisasi dasar terhadap sikap orang tua pada masa pandemi COVID-19.

Penelitian sebelumnya juga menyatakan bahwa ada pengaruh penyuluhan melalui media booklet tentang imunisasi dasar lengkap terhadap sikap orang tua menjadi lebih baik setelah diberikan media booklet (Agnes dkk., 2011).

Beberapa faktor yang menyebabkan layanan imunisasi dasar tidak terpenuhi masa pandemi COVID19 ini, faktor yang mempengaruhi utama adalah pengetahuan ibu balita tentang pentingnya kelengkapan imunisasi dasar. Pengetahuan tentang akibat apabila tidak melengkapi imunisasi dasar akan timbul penyakit-penyakit berbahaya akan mempengaruhi 
Jurnal Ilmiah Ibnu Sina, 6(2), Oktober 2021, 312-321

p-ISSN: 2502-647X; e-ISSN: 2503-1902

kembang tumbuh balita (Alsuhaibani

\& Alaqeel, 2020). Sikap tentang pentingnya imunisasi dasar, motivasi ibu balita agar tetap datang ke pelayanan kesehatan untuk melakukan imunisasi dasar dengan menerapkan protokol kesehatan (Agnes, 2011; Alsuhaibani \& Alaqeel, 2020).

Sebagian besar orang tua menilai dengan berbagai alasan menyatakan pelayanan imunisasi di Posyandu maupun kunjungan rumah lebih aman dibandingkan pelayanan imunisasi di fasilitas kesehatan. Beberapa responden menyatakan bahwa fasilitas pelayanan kesehatan menawarkan layanan untuk anakanak yang sakit dan sehat, mereka tidak mau mengunjungi puskesmas karena takut tertular COVID-19, ini sejalan dengan penelitian alasan penundaan imunsasi adalah karena kecemasan dan rasa khawatir. Oleh karena itu, ada permintaan yang tinggi dari masyarakat untuk melanjutkan layanan imunisasi di Posyandu, dan permintaan yang tinggi untuk kunjungan dari rumah ke rumah untuk skrining dan imunisasi.
Petugas kesehatan di berbagai tingkatan diharapkan dapat meningkatkan pengetahuan, membangun kepercayaan dan kredibilitas, serta mendorong terciptanya sikap, perilaku dan kepercayaan yang tepat terhadap informasi imunisasi rutin pada masa pandemi COVID-19.

Beberapa upaya yang dapat dilakukan adalah antara lain: a. Membangun hubungan yang baik dengan tokoh-tokoh utama media masa, terutama yang berfokus pada isu-isu kesehatan, b. Memberikan orientasi yang benar pada media massa, c. Fokus pada pentingnya upaya memverifikasi berita sebelum disebarluaskan, d. Menekankan pentingnya peran media massa, e. Menyiapkan nomor kontak pejabat fungsional di fasilitas kesehatan (kepala puskemas/ kepala dinas kesehatan kabupaten/ kota/ provinsi) yang telah ditunjuk sebagai rujukan utama yang bisa dihubungi oleh media massa (Kemenkes, 2020; UNICEF, 2020). 
Jurnal Ilmiah Ibnu Sina, 6(2), Oktober 2021, 312-321

p-ISSN: 2502-647X; e-ISSN: 2503-1902

\section{KESIMPULAN}

Edukasi media booklet tentang imunisasi dasar adanya pengaruh $(\rho=0,001)$ terhadap pengetahuan dan sikap orang tua masa pandemi COVID-19.

\section{DAFTAR PUSTAKA}

Agnes, W. P., 2011. Pengaruh Penyuluhan Imunisasi Terhadap Peningkatan Pengetahuan Dan Sikap Ibu Tentang Imunisasi Dasar Lengkap Pada Bayi Sebelum Usia 1 Tahun. Thesis. Universitas Negeri Surakarta

Anderson, Ronald, H., 2006. Pemilihan Dan Pengembangan Media Untuk Pembelajaran, Raja Grafindo Persada, Jakarta, halaman 21 .

Kementrian Kesehatan. 2020, Petunjuk Teknis Pelayanan Imunisasi Pada Masa Pandemi Covid-19, Infeksi Emerging, Vol 2, Edisi Juni, halaman 11.

Kementerian Kesehatan dan UNICEF Indonesia. 2020, Imunisasi Rutin Pada Anak Selama Pandemi Covid-19 Di Indonesia: Persepsi Orang tua dan Pengasuh, halaman 1,2.

Kementrian Kesehatan. 2020, Petunjuk Teknis Pelayanan Imunisasi Pada Masa Pandemi Covid-19, Infeksi Emerging, Vol 2, Edisi Juni, halaman 14.

Mohammed Alsuhaibani and Aqeel Alaqeel. 2020. Impact Of The Covid-19 Pandemic On

\section{UCAPAN TERIMAKASIH}

Kepada Yayasan Borneo Lestari, STIKES Borneo Lestari, Puskesmas Sungai Besar yang telah membantu terlaksananya penelitian.

Routine Childhood Immunization In Saudi Arabia Department of Pediatrics, College Of Medicine, Qassim University, Qassim 51452, Saudi

Arabiaa.alaqeel@qumed.edu.sa

Ninik Azizah, dkk. 2011. Hubungan Tingkat Pengetahuan Ibu Tentang Pentingnya Imunisasi Dasar Dengan Kepatuhan Melaksanakan imunisasi Di Bps Hj. Umi Salamah Di Desa Kauman,

Peterongan,Jombang.Fakultas

Ilmu Kesehatan UNIBDU, Jombang.

Safitri. 2019. Penyuluhan Tentang Imunisasi Pada Bayi Di Posyandu Kasih Ibu Didesa Palawan Kabupaten Sarolangon. Jurnal Abdimas Kesehatan (JAK) Jambi Vol. 1 No. 2

Sugiyono. 2012. Metode

Penelitian Kuantitatif

Kualitatif Dan R\&B. Alfabeta Bandung, halaman 8.

Tyas Dwi Puspita Hati. 2017. Pengaruh Penyuluhan Dengan Media Booklet Terhadap Pengetahuan Dan 
Jurnal Ilmiah Ibnu Sina, 6(2), Oktober 2021, 312-321

p-ISSN: 2502-647X; e-ISSN: 2503-1902

Sikap Ibu Anak Balita Tentang

Keluarga Sadar Gizi di Desa

Grogol, Kecamatan Weru,

Kabupaten Sukoharjo. Fakultas

Ilmu

Kesehatan

Muhammadiyah, Surakarta.

Usman Arif. 2021. Penyuluhan Kesehatan Tentang Imunisasi

Dasar Lengkap Pada Masa

Pandemi Covid-19 Di Desa

Kelebuh Wilayah Kerja

Puskesmas Batu nyala. Jornal

Of Community Engagement in Healty. Vol.4 No.1. Halaman.259-263.

Virginia Nur Ayu. 2020. Imunisasi Dasar Dalam Masa Pandemi Covid-19. Fakultas Kedokteran Lampung.

Yeni Anggraini dan Kurnia Agustin. 2020. Efektivitas Pengetahuan Orangtua Batita Terhadap Ketepatan Imunisasi Dasar Dan Booster Pada Masa Pandemi Covid-19 Di Posyandu Wilayah Kerja Puskesmas Colomadu. Jurnal Maternal II Vol. IV No. 2. 